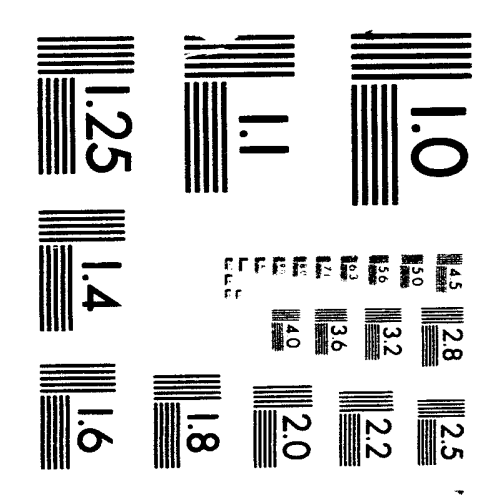



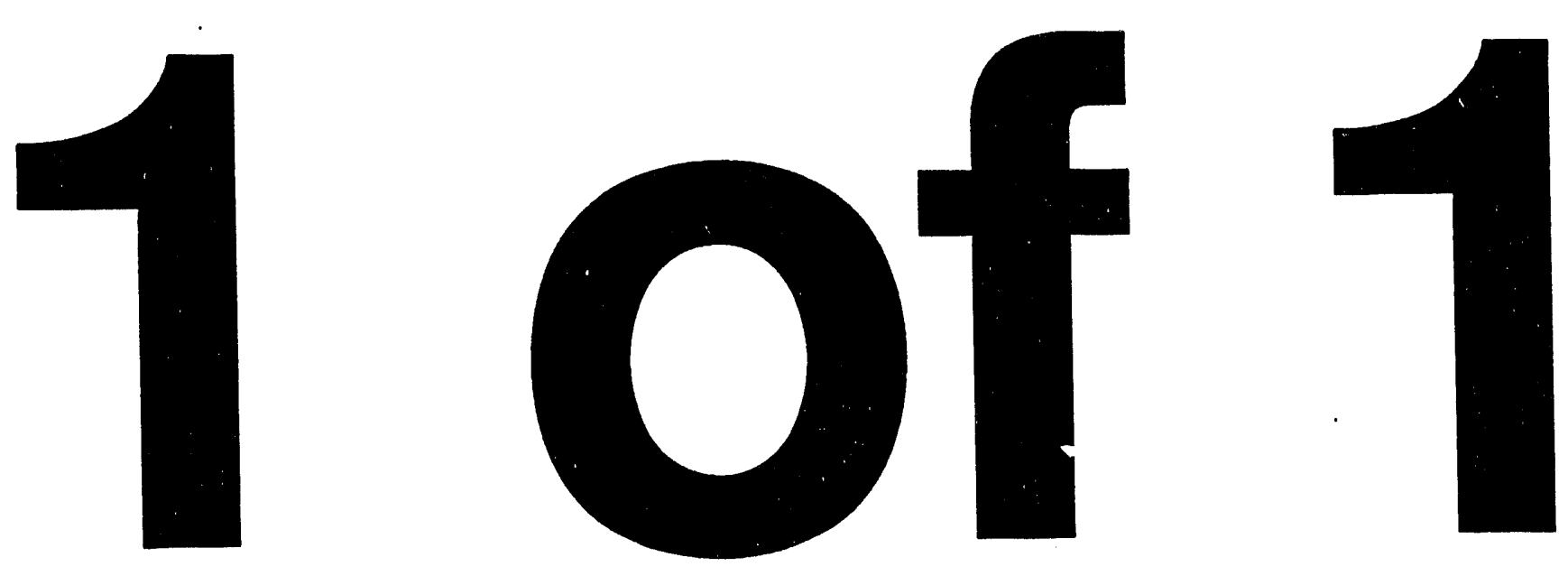


\title{
The theory of stabilization of sawtooth oscillations in TFTR supershots
}

\author{
L. Zakharov, F. Levinton \\ Princeton Plasma Physics Laboratory, P.O.Box 451, Princeton, NJ 08543-0451 \\ S. Migliuolo, B. Rogers \\ Massachusetts Institute of Technology, Cambridge, MA 02139
}

(October 21, 1993)

\begin{abstract}
A theoretical concept of onset and stabilization of sawtooth oscillations in tokamaks is formulated based on the analysis of supershots in the Tokamak Fusion Test Reactor [1] (TFTR). While the linear theory, which includes the ideal $m=1$ mode, contradicts the experimental data, the criterion of $\omega_{*}$-stabilization of the collisionless $m=1$ reconnection mode determines an operational space for the sawtooth-free phase in TFTR.
\end{abstract}

52.35.Py, 52.30.Fb, 52.55.Fa 
Sawtooth oscillations [2] in tokamaks represent one of the best examples of reconnection in plasmas [3] and have been the focus of extensive theoretical studies. Nevertheless, a detailed check of the theory against experiments has become possible only recently, after internal poloidal magnetic field measurements were performed in various tokamaks. Among these, the Tokamak Fusion Test Reactor [1] (TFTR) is distinguished due to its simple (circular) geometry and high plasma temperature (more than $10 \mathrm{keV}^{\prime} \mathrm{s}$ ) which simplify to some extent the theoretical analysis. Measurements of the local magnetic pitch angle $B_{\theta}(R) / B$, based on the motional Stark effect (MSE), is now a routine diagnostic in TFTR [4] ( $B_{\theta}, B$ are the poloidal and toroidal magnetic fields, $R$ is the major radius). Together with TRANSP [5] analyses of plasma profiles (the density $n$, ion and electron pressures $p_{i, e}$, and pressure $p_{h o t}$ of hot beam particles), MSE data allow a reliable reconstruction of the plasma current profile and the magnetic configuration, which can be used to perform a quantitative comparison of the theory with experiment.

At present, reconnection theory faces considerable difficulties explaining the sawtooth phenomenon because experiments do not confirm a theoretically predicted jump in the central safety factor $q_{0}$ to unity during the sawtooth crash $[6]\left(q(r) \equiv r B /\left(R B_{\theta}\right), r\right.$ is the plasma minor radius).

In this paper, we limit ourselves to the simplest (but practically very important) question of what the stability conditions are that determine the operational space for sawtoothing and sawtooth-free phases in tokamaks. We rely on the fact that the initial stage of reconnection is not rejected by experiments and use the theory of the $m=1$ reconnection mode in our stability analysis.

A number of supershots $(64541,64547,65610-65613,68257,68262,68263)$, exhibiting both sawtooth free periods and well established sawteeth have been analysed in TFTR. Starting with the one-fluid magnetohydrodynamic (MHD) model, we immediately found that the sawtooth onset and stabilization in these supershots exhibit tendencies which are opposite to predictions of this model. In particular, the sawtooth free phases in experiments correspond to peaked pressure profiles with central $\beta_{1, \text { pol }} \sim 1-1.5$, which is much higher 
than the theoretical threshold [7] 0.3 for excitation of the ideal $m=1$ mode $\left(\beta_{1, p o l}\right.$ is defined below by Eq.(3)).

We thus are led to consider a more advanced description, namely the two-fluid model [8], which requires a minimum of additional experimental information. Unlike one-fluid MHD, this model includes the effects of finite drift frequencies, $\omega_{*}$, which are proportional to the plasma profile gradients. These frequencies lower the growth rate of the $m=1$ mode and can, in fact, lead to stability.

There are several types of modes related to reconnection: ideal, collisionless and resistive $m=1$ modes. They are characterized by a rigid shift $\xi_{0}$ of the plasma inside the radius $r_{1}$ of the mode resonant surface (where $q(r)=1$ ) and by the resulting presence of a singular layer at this radius.

The growth rate $\gamma_{I}$ of the ideal mode is

$$
\gamma_{I} \tau_{A}=q_{1}^{\prime} \lambda_{H} / \sqrt{3}
$$

where $\tau_{A}=R \sqrt{4 \pi n_{i} m_{i}} / B$ is the poloidal Alfven time, $q_{1}^{\prime} \equiv q^{\prime}\left(r_{1}\right)=d q(r) /\left.d r\right|_{r_{1}}$ is the radial derivative of the safety factor and $\lambda_{H}$ is a width of the inertial singular layer

$$
\begin{aligned}
& \lambda_{H} \simeq-\frac{3 \pi}{q_{1}^{\prime}} \frac{r_{1}^{2}}{R^{2}}\left(0.3^{2}-\beta_{1, p o l}^{2}\right), \\
& \beta_{1, p o l}=\frac{8 \pi\left[<p>-p\left(r_{1}\right)\right]}{B_{\theta}^{2}\left(r_{1}\right)},
\end{aligned}
$$

related to the well-known ideal stability criterion [7], $\lambda_{H} \leq 0$. In Eq. (3), $<p>$ is the averaged total pressure, $p \equiv p_{e}+p_{i}+p_{\text {hot }}$, inside the $q=1$ surface. (In our calculations of $\lambda_{H}$, the full original version [7] of the ideal stability criterion was used). For TFTR supershots the typical value of $\lambda_{H}$ is positive and about $1 \mathrm{~cm}$.

The collisionless reconnection mode has a linear growth rate [9-11]

$$
\gamma \tau_{A}=q_{1}^{\prime} \rho_{s}\left(\frac{2 c}{\pi \omega_{p e} \rho_{s}}\right)^{1 / 3}
$$

in the regimes with $\rho_{s} \omega_{p e} / c=\sqrt{\beta_{1} m_{i} /\left(2 m_{e}\right)}>1\left(m_{e}, m_{i}\right.$ are the electron and ion masses). Here $\rho_{s}=\sqrt{\left(T_{e}+T_{i}\right) / m_{i}} / \Omega_{c i}$ is the ion-sound Larmor radius, $\omega_{p e}$ is the plasma frequency 
and the local $\beta_{1}=8 \pi p / B^{2}$ is calculated at the $q=1$ surface. For TFTR $\rho_{s} \sim 0.5 \mathrm{~cm}$. The resistive analog of this mode becomes unimportant in comparison with the collisionless mode under condition

$$
q_{1}^{\prime} r_{1} \frac{c^{3}}{\omega_{p e}^{3} r_{1}^{3}}\left(\frac{\beta_{1} m_{i}}{\pi m_{e}}\right)^{1 / 3}>>S^{-1} \equiv \frac{\tau_{A} c^{2} \eta}{4 \pi r_{1}^{2}}
$$

where $S \simeq 10^{8}$ is the Lundquist (magnetic Reynolds) number. This condition is typically fulfilled for TFTR supershots and so we neglect the resistive reconnection mode.

It is necessary to mention that the collisionless and resistive $m=1$ modes arise in the main tokamak approximation (neglecting corrections of order $\epsilon \equiv r_{1} / R \simeq B_{\theta} / B \ll 1$ ). In contrast, the ideal $m=1 \mathrm{kink}$ mode is marginally stable in the main approximation and becomes unstable only due to $\epsilon^{2}$ corrections. For this reason, during the nonlinear stage, when $\xi_{0}>\left\{\rho_{s}, \lambda_{H}\right\}$, the mode "forgets" about linear stability properties of the ideal mode [12] and behaves as a collisionless reconnection mode with a universal nonlinear growth rate $[13]$

$$
\gamma_{n l i n} \tau_{A} \simeq q_{1}^{\prime} \rho_{s}
$$

Two-fluid linear theory predicts a stabilization of the collisionless reconnection mode as well as the ideal mode by $\omega_{*}$-effects $[14,10]$. It occurs when the singular layer equation [8]

$$
\begin{aligned}
& {\left[\left(\frac{\omega\left(\omega-\omega_{* i}\right) \rho_{s}^{2}}{\left(\omega-\omega_{* e}^{n}\right)\left(\omega-\omega_{* i}^{n}\right)}-\frac{\omega^{2}\left(\omega-\omega_{* i}\right) \tau_{A}^{2} c^{2}}{\left(\omega-\omega_{* e}\right) \omega_{p e}^{2} q^{\prime 2} x^{2}}\right) Z^{\prime}\right]^{\prime}} \\
& =\left(1-\frac{\omega\left(\omega-\omega_{* i}\right) \tau_{A}^{2}}{q^{\prime 2} x^{2}}\right) Z-\frac{2 \lambda_{H}}{\sqrt{3} \pi x^{2}} \int_{C}^{\infty} Z d x
\end{aligned}
$$

has a solution only for a real eigenvalue $\omega$ with boundary conditions $Z_{x=0}=0, Z_{x=0}^{\prime}=0$ and $Z_{x=\infty}=0$ in the interval $0<\omega<\omega_{* i}$, corresponding to the reconnection root. Here, $\omega_{*}^{\prime}$ 's represent drift frequencies

$$
\begin{aligned}
& \omega_{* i}=-\frac{c P_{i}^{\prime}}{n e r_{1} B}, \quad \omega_{* i}^{n}=-\frac{c P_{i} n^{\prime}}{n^{2} e r_{1} B}, \quad P_{i} \equiv p_{i}+p_{h o t} \\
& \omega_{* e}=\frac{c p_{e}^{\prime}}{n e r_{1} B}, \quad \omega_{* e}^{n}=\frac{c T_{e} n^{\prime}}{n e r_{1} B}
\end{aligned}
$$


(we have included beam particles in the ion species, although the use of fluid theory for the hot particles is problematic).

The stability condition can be written in a symbolic form

$$
r_{1} q_{c r}^{\prime}>r_{1} q_{1}^{\prime}
$$

where $r_{1} q_{1}^{\prime}$ is a shear of the $q(r)$-profile, while the left hand side is a complicated function of $\omega_{*}$ 's, $\beta_{1}$ and $\lambda_{H}, q_{c r}^{\prime}=q_{c r}^{\prime}\left(\omega_{* i}, \omega_{* i}^{n}, \omega_{* e}, \omega_{* e}^{n}, \beta_{1}, \lambda_{H}\right)$, calculated numerically by solving equation (7).

In the analysis, the TRANSP code has been used to determine gradients of the plasma profiles entering in $q_{c r}^{\prime}$. A special code based on the Electrodynamical Moment EQuilibrium (EMEQ) approach [15] has been developed to reconstruct the TFTR equilibria using MSE data. This provides the $q(r)$-profile and allows the $\lambda_{H}$-parameter to be calculated.

Three versions of criterion (10) have been compared against the experimental data. The first is Eq. (10) exactly as described above: $r_{1} q_{c r, I}^{\prime} \equiv r_{1} q_{c r}^{\prime}>r_{1} q_{1}^{\prime}$. It is found to be violated in all the discharges during their supershot phases due to the presence of an unstable ideal $m=1$ mode $\left(\lambda_{H}>0\right)$, which is almost always dominant over the collisionless reconnecting mode. Thus, this criterion is in contradiction with the existence of sawteeth-free phases in these supershots. For stable shot 65611 , where $q_{c r, I}^{\prime}$ is about three times less than the actual value of $q_{1}^{\prime}$, the contradiction cannot be explained by uncertainties in experimental data, profile reconstruction or theoretical estimates (Fig. 1c).

The second version of Eq. (10) includes the kinetic effects of energetic beam particles: $\lambda_{H} \rightarrow \lambda_{H}+\lambda_{K}$, where

$$
\lambda_{K}=\frac{r_{1}}{q_{1}^{\prime 2} r_{1}^{2}}\left(\frac{r_{1}}{R}\right)^{3 / 2} \frac{8 \pi}{B_{\theta}^{2}\left(r_{1}\right)} \int_{0}^{r_{1}}\left(\frac{r}{r_{1}}\right)^{3 / 2} p_{h o t}^{\prime} d r
$$

This form [16] of $\lambda_{K}$ neglects the $\omega$ dependence of this parameter and overestimates the stabilizing effect of isotropic hot particles. Nevertheless, this modification only moderately improved the situation. For shot 65611 (Fig. 1c), the value of $\left.q_{c r, I I}^{\prime} \equiv q_{c r}^{\prime}\right|_{\lambda_{H} \neq 0, \lambda_{K} \neq 0}$ is still two times less than the actual shear. 
We also compared a third version of criterion (10), where we put $\lambda_{H}=0$ and $\lambda_{K}=0$, thus neglecting the (dominant) linear ideal mode

$$
\left.r_{1} q_{c r, I I I}^{\prime} \equiv r_{1} q_{c r}^{\prime}\right|_{\lambda_{H}=\lambda_{K}=0}>r_{1} q_{1}^{\prime}
$$

Earlier [13], a simplified form of this criterion (assuming equal temperatures $T_{e}=T_{i}$ )

$$
r_{1} q_{c r, I I I}^{\prime} \simeq 1.4 \beta_{1}^{2 / 3}\left|\frac{n^{\prime} R}{n}\right|^{2 / 3}\left|\frac{p^{\prime} R}{p}\right|^{1 / 3}>r_{1} q_{1}^{\prime}
$$

was used in a comparison of the two-fluid theory with TFTR TRANSP data (including $q(r)$ profile). In (13), all quantities are calculated at the $q=1$ surface. In the present analysis we did not use this simplification, but the analytical form (13) is numerically close to criterion (12) and reflects the stabilization of sawteeth by an increase in $\beta_{1}$ and the peakedness factors of $n(r)$ - and $p(r)$-profiles.

Criterion (12) (which is inconsistent with linear theory in the present case) is found to be in good qualitative agreement with the analyzed shots. It is fulfilled in the supershot phases of discharges $64541,65611,68257$, which have no sawteeth, and is violated in the shot 64547, which has large sawteeth during the supershot phase. Moreover, criterion (12) reasonably well predicts the time of transition from the sawtooth-free to the sawtoothing phase in shots $65610-65612,68262,68263$ (the details of that will be described in a separate publication).

Based on this comparison, we conclude that the linear theory of the $m=1$ mode is in contradiction with sawtooth stabilization in TFTR supershots. The success of criterion (12) leads us to the following concept concerning sawtooth oscillations, in which the nonlinear properties of the $m=1$ mode play a crucial role.

We assume that $\omega_{*}$-stabilization survives during the nonlinear stage of $m=1$ reconnection because of an emerging jump in the plasma pressure profile across the singular layer. The nonlinear reconection mode is a prolongation of a pure linear collisionless reconnecting $m=1$ mode. Although there is no theory of the nonlinear $\omega_{*}$-stabilization at present, we can presume that criterion (12) roughly describes this nonlinear $\omega_{*}$ stabilization. 
This concept can be described by a model equation for the evolution of the central core displacement, where we assume for simplicity that the growth rate of the ideal $m=1$ mode is additive to that of the collisionless mode

$$
\begin{aligned}
\tau_{A} \frac{d \xi_{0}}{d t} & =-f_{1} \rho_{s}\left(q_{c r, I I I}^{\prime}-q^{\prime}\right) \xi_{0}+f_{2} q^{\prime} \frac{\lambda_{H}+\lambda_{K}}{\sqrt{3}} \xi_{0} \\
& \equiv-\frac{d U\left(\xi_{0}\right)}{d \xi_{0}}
\end{aligned}
$$

Here, the function $f_{1} \equiv f_{1}\left(\xi_{0} / \rho_{s}\right)$ is of the order unity and describes the transition of the collisionless reconnection mode from linear, $f_{1}(0)=\left[2 c /\left(\pi \omega_{p e} \rho_{s}\right)\right]^{1 / 3}$, to nonlinear regime, $f_{1}\left(\xi_{0} / \rho_{s} \gg 1\right)=O(1)$, while the function $f_{2} \equiv f_{2}\left(\xi_{0} / \lambda_{H}\right)$ describes the cancellation of the effect of the ideal mode during the nonlinear stage

$$
f_{2}(0)=1, \quad f_{2}\left(\xi_{0} / \lambda_{H} \gg 1\right)=0
$$

Both of these functions have not yet been determined by the theory, but for our purposes only their linear and nonlinear limits are essential. In Eq.(14), extrema of $U\left(\xi_{0}\right)$ determine the stationary points (Fig. 2).

The first term on the right hand side of (14) determines the stability with respect to the sawtooth crash itself. The second term determines the influence of the ideal $m=1$ mode during the linear phase. For TFTR stable $\left(q_{c r, I I I}^{\prime}>q_{1}^{\prime}\right)$ supershots, the second term is destabilizing, $\lambda_{H}+\lambda_{K}>0$, and Eq.(14) predicts the existence of a saturated $m=1$ mode (Fig. 2a) with an amplitude related to the $\lambda_{H}$ parameter.

This prediction has been checked for the analysed discharges. For most of the supershots mentioned above the parameter $\lambda_{H} \leq 1 \mathrm{~cm}$ and no oscillations were detected. For shot 65611, $\lambda_{H} \simeq 2.5 \mathrm{~cm}$ and a harmless $m=1$ mode was observed (Fig. 3), thus supporting the concept. It is possible that the "snakes" observed on several tokamaks have the same nature as this saturated mode but with a larger $\lambda_{H}$ parameter.

According to Eq.(14), sawtooth crashes occur only when criterion (12) is violated. In that cases the second term may provide stability to small perturbations if $\lambda_{H}+\lambda_{K}<0$ (ideal mode is stabilized). But this state is expected to be metastable at best (Fig. 2b) and 
any finite perturbation or violation of linear stability will trigger a crash. This scenario is consistent with previously proposed triggering mechanisms of the fast crash $[13,17]$.

The concept described, although consistent with the basic linear and nonlinear properties of the $m=1$ reconnection mode and as well with experimental data, is still based on several assumptions. In particular, the existence of nonlinear $\omega_{*}$-stabilization requires qualitative and quantitative theoretical justification. Also, the use of fluid theory for the hot particles is problematic. Nevertheless, we believe this concept answers the question of what determines the stable operational space against sawtooth oscillations, namely criterion (12) or (13), reasonably well. Also, it predicts an achievable stable central $q(0) \simeq 1-0.5 r_{1} q_{c r, I I I}^{\prime}$ (for parabolic $q$-profiles).

This work was supported by United States Department of Energy Contracts No. DEAC02-76-CHO-3073, and DE-FG02-91ER-54109 and by the U.S.D.O.E. Fusion Energy PostDoctoral Research Program. 


\section{REFERENCES}

[1] K. McGuire, V. Arunasalam, C.W. Barnes, M.G. Bell, M. Bitter, R. Boivi , N.L. Bretz, R. Budny, C.E. Bush, A. Cavallo, T.K. Chu, S.A. Cohen, P. Colestock, S.L. Davis, D.L. Dimock, H.F. Dylla, P.C. Efthimion, A.B. Ehrhardt, R.J. Fonck, E.D. Fredrick-

son, H.P. Furth, G. Gammel, R.J. Goldston, G.J. Greene, B. Grek, L.R. Grisham, G.W. Hammett, R.J. Hawryluk, H.W. Hendel, K.W. Hill, E. Hinnov, D.J. Hoffman, J.C. Hosea, R.B. Howell, H. Hsain, R.A. Hulse, A.C. Janos, D.L. Jassby, F.C. Jobs, D.W. Johnson, L.C. Johnson, R. Kaita, C. Kieras-Phillips, S.J. Kilpatrick, P.H. Lamarche, B. LeBlanc, D. Manos, D.K. Mansfield, E. Mazzucato, M.P. McCarthy, D.C. McCune, D.H. McNeill, D.M. Meade, S.S. Medley, D.R. Mikkelsen, D.A. Monticello, R.W. Motley, D. Mueller, J. Murphy, Y. Nagayama, R. Nazikian, E.B. Neischmidt, D.K. Owens, H.K. Park, W. Park, S. Pitcher, A.T. Ramsey, M.H. Redi, A.L. Roquemore, P.H. Rutherford, G. Schilling, J. Schivell, G.L. Schmidt, S.D. Scott, J. Sinnis, J.E. Stevens, B.C. Stratton, W. Stodiek, E.J. Synakowski, W.M. Tang, G. Taylor, J.I. Timberlake, H.H. Towner, M. Ulrickson, S. von Goeler, R.M. Wieland, M. Williams, J.R. Wilson, K.L. Wong, M. Yamada, S. Yoshikawa, K.M. Young, M.C. Zarnstorff, S.J. Zweben, Phys. Fluids B 2, 1287 (1990).

[2] S. von Goeler, W. Stodiek, N. Sauthoff, Phys. Rev. Lett. 33, 1201 (1974).

[3] B.B. Kadomtsev, Fiz. Plasmy 1, 710 (1975) [Sov. J. Plasma Physics 1, 389 (1975)].

[4] F.M. Levinton, S.H. Batha, M. Yamada, M.C. Zarnstorff, Phys. Fluids B 5, 2554 (1993).

[5] M.C. Zarnstorff, K. McGuire, M.G. Bell, B. Grek, D. Johnson, D. McCune, H. Park, A. Ramsey, and G. Taylor, Phys. Fluids B 2, 1852 (1990).

[6] J. O'Rourke, Plasma Phys. Cont. Fusion 33, 289 (1991).

[7] M.N. Bussac, R. Pellat, D. Edery, J.L. Soule, Phys. Rev. Lett. 35, 1638 (1975).

[8] L. Zakharov, B. Rogers, Phys. Fluids B 4, 3285 (1992). 
[9] J.F. Drake, Phys. Fluids 21, 1777 (1978).

[10] F. Porcelli, Phys. Rev. Lett. 66, 425 (1991).

[11] H.L. Berk, S.M. Mahajan, Y.Z. Zhang, Phys. Fluids B 3, 351 (1991).

[12] F.L. Waelbroeck, Phys. Fluids B 1, 2372 (1989).

[13] L. Zakharov, B. Rogers, S. Migliuolo, Phys. Fluids B 5, 2498 (1993).

[14] G. Ara, B. Basu, B. Coppi, G. Laval, M.N. Rosenbluth, and B.V. Waddell, Annals of Phys. 112, 443 (1978).

[15] L.E. Zakharov, "Method of Electrodynamic Moments for Equilibrium Calculations in a Toroidal Plasma", Preprint of the Kurchatov Institute of Atomic Energy IAE-4114/6, Moscow (1985).

[16] B. Coppi, S. Migliuolo, F. Pegoraro, F. Porcelli, Phys. Fluids B 2, 927 (1990).

[17] J.A. Wesson, A.W. Edwards, R.S. Granetz, Nucl. Fusion 31, 111 (1991). 


\section{FIGURES}

FIG. 1. a) Central $\beta_{1, p o l}$ and b) ideal $m=1$ mode scale length $\lambda_{H}$ for stable TFTR supershots; c) theoretical critical shears and reconstructed shear in stable supershot 65611 .

FIG. 2. Function $U\left(\xi_{0}\right)$ (Eq.(14)) a) for stable supershots: $r_{1} q_{c r, I I I}^{\prime}>r_{1} q_{1}^{\prime}, \lambda_{H}+\lambda_{K}>0$, and b) for metastable case, $r_{1} q_{c r, I I I}^{\prime}<r_{1} q_{1}^{\prime}, \lambda_{H}+\lambda_{K}<0$, which is susceptible to the sawtooth crash.

FIG. 3. Contours of electron cyclotron emissivity $T_{e}(R, t)=$ const indicating the presence of a saturated $m=1$ mode in shot 65611 . 


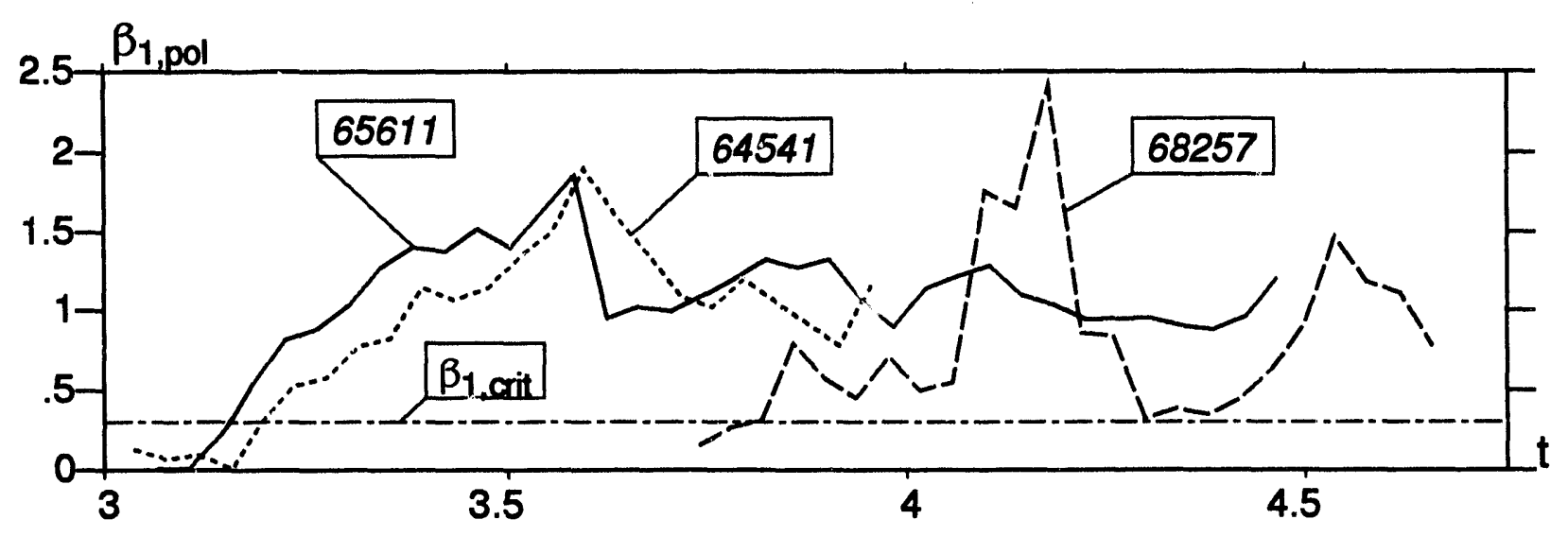

a)
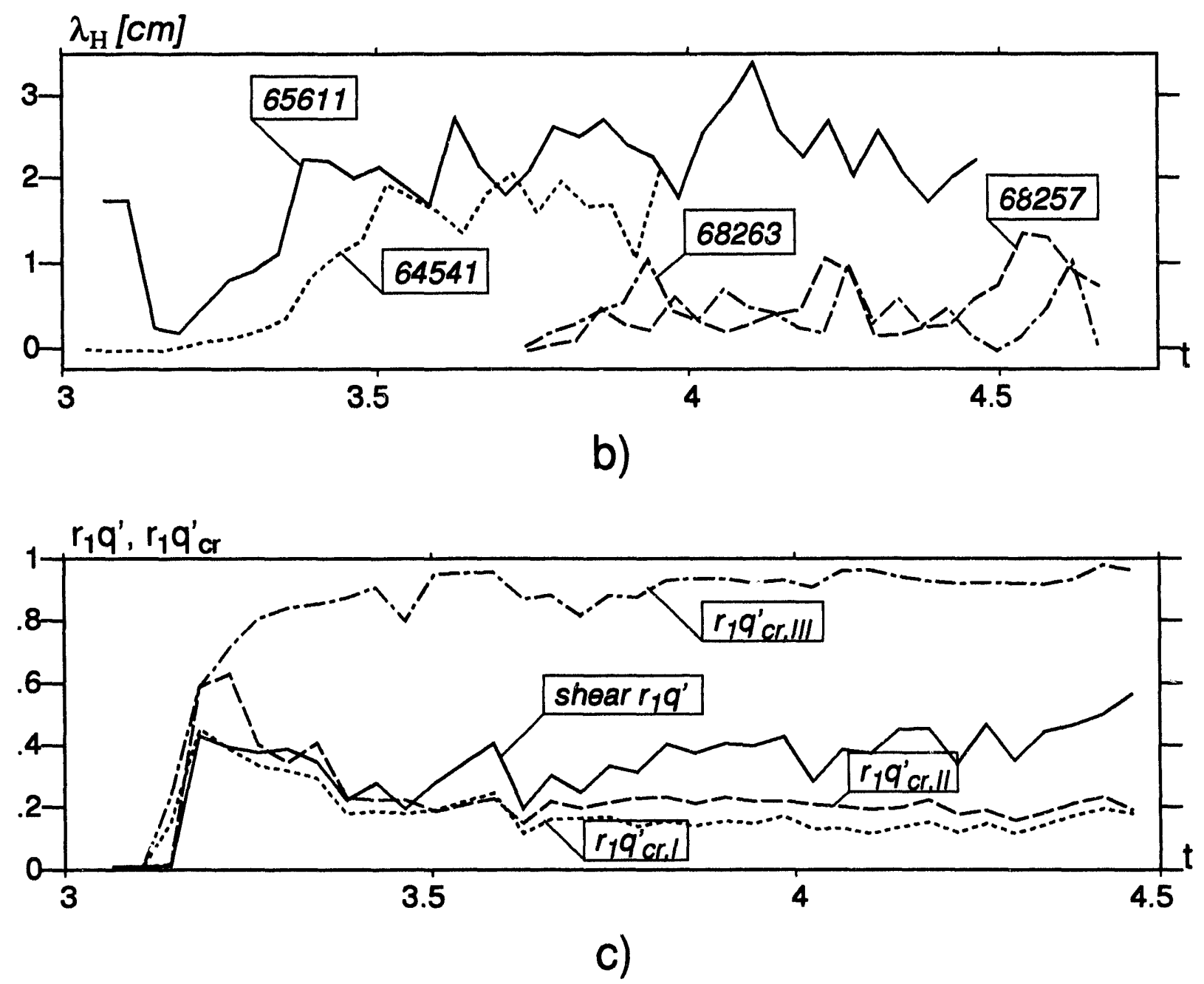

Fig.1 


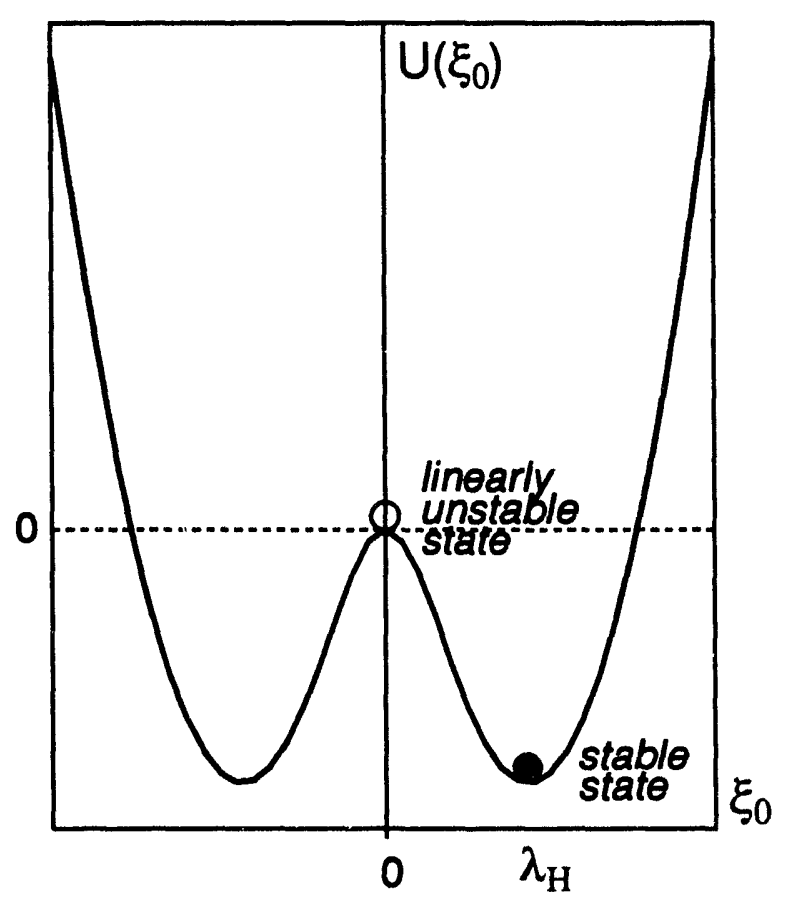

a)

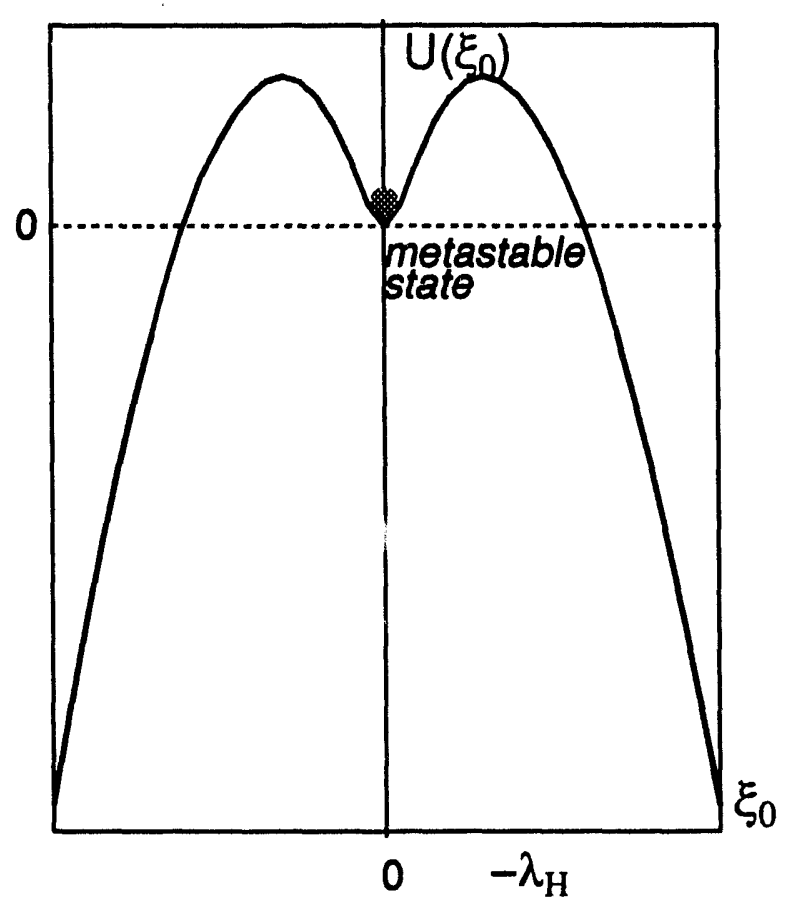

b)

Fig.2 


\section{TFTR 65611}

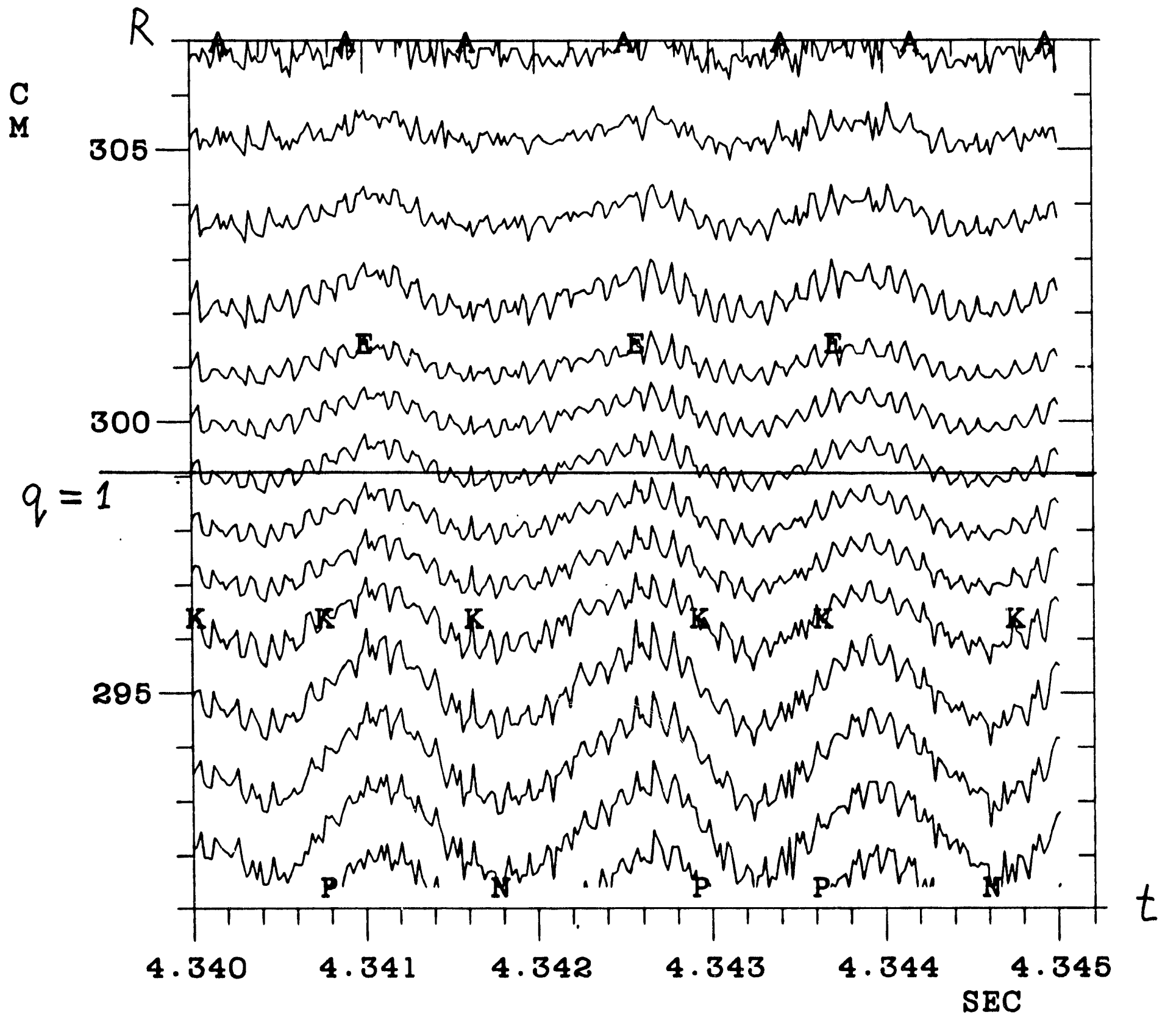

Fig.3 
Dr. F. Paoloni, Univ. of Wollongong, AUSTRALIA

Prof. M.H. Brennan, Univ. of Sydney, AUSTRALIA

Plasma Research Lab., Australian Nat. Univ., AUSTRALIA

Prof. I.R. Jones, Flinders Univ, AUSTRALIA

Prof. F. Cap, Inst. for Theoretical Physics, AUSTRIA

Prof. M. Heindler, Institut tür Theoretische Physik, AUSTRIA

Prof. M. Goossens, Astronomisch instituut, BELGIUM

Ecole Royale Militaire, Lab. de Phy. Plasmas, BELGIUM

Commission-European, DG. XII-Fusion Prog., BELGIUM

Prof. R. Bouciqué, Rijksuniversiteit Gent, BELGIUM

Dr. P.H. Sakanaka, Instituto Fisica, BRAZIL

Prof. Dr. I.C. Nascimento, Instituto Fisica, Sao Paulo, BRAZIL Instituto Nacional De Pesquisas Espaciais-INPE, BRAZIL

Documents Otfice. Atomic Energy of Canada Ltd., CANADA

Ms. M. Morin, CCFMTokamak de Varennes, CANADA

Dr. M.P. Bachynski, MPB Technologies, Inc., CANADA

Dr. H.M. Skarsgard, Univ. of Saskatchewan, CANADA

Prof. J. Teichmann, Univ. of Montreal, CANADA

Prof. S.R. Sreenivasan, Univ. of Calgary, CANADA

Prof. T.W. Johnston, INRS-Energie, CANADA

Dr. R. Bolton, Centre canadien de fusion magnétique, CANADA

Dr. C.R. James, Univ. of Alberta, CANADA

Dr. P. Lukác, Komenského Universzita, CZECHO-SLOVAKIA

The Librarian, Culham Laboratory, ENGLAND

Library, R61, Ruthertord Appleton Laboratory, ENGLAND

Mrs. S.A. Hutchinson, JET Library, ENGLAND

Dr. S.C. Sharma, Univ. of South Pacific, FIJI ISLANDS

P. Mähönen, Univ. of Heisinki, FINLAND

Prof. M.N. Bussac, Ecole Polytechnique, FRANCE

C. Mouttet, Lab. de Physique des Milieux lonisés, FRANCE

J. Radet, CEN/CADARACHE - Bat 506, FRANCE

Prof. E. Economou, Univ. of Crete, GREECE

Ms. C. Rinni, Univ. of loannina, GREECE

Preprint Library, Hungarian Academy of Sci., HUNGARY

Dr. B. DasGupta, Saha Inst. of Nuclear Physics, INDIA

Dr. P. Kaw, Inst. for Plasma Research, INDIA

Dr. P. Rosenau, Israel Inst. of Technology, ISRAEL Librarian, Intemational Center for Theo Physics, ITALY

Miss C. De Palo, Associazione EURATOM-ENEA, ITALY

Dr. G. Grosso, Istituto di Fisica del Plasma, ITALY

Prof. G. Rostangni, Istituto Gas lonizzati Del Cnr, ITALY
Dr. H. amato, Toshiba Res \& Devel Center, JAPAN

Prof. I. Kawakami, Hiroshima Univ., JAPAN

Prof. K. Nishikawa, Hiroshima Univ., JAPAN

Librarian, Naka Fusion Research Establishment, JAERI, JAPAN

Director, Japan Atomic Energy Research Inst., JAPAN

Prot. S. Itoh, Kyushu Univ., JAPAN

Research Info. Ctr., National Instit. for Fusion Science, JAPAN

Prof. S. Tanaka, Kyoto Univ., JAPAN

Library, Kyoto Univ., JAPAN

Prof. N. Inoue, Univ. of Tokyo, JAPAN

Secretary, Plasma Section, Electrotechnical Lab., JAPAN

S. Mori, Technical Advisor, JAERI, JAPAN

Dr. O. Mitarai, Kumamoto Inst. of Technology, JAPAN .

Dr. G.S. Lee, Korea Basic Sci. Cr., KOREA

J. Hyeon-Sook, Korea Atomic Energy Research Inst., KOREA

D.I. Choi, The Korea Adv. Inst. of Sci. \& Tech., KOREA

Prof. B.S. Liley, Univ. of Waikato, NEW ZEALAND

Inst of Physics, Chinese Acad Sci PEOPLE'S REP. OF CHINA

Library, Inst. of Plasma Physics, PEOPLE'S REP. OF CHINA

Tsinghua Univ. Library, PEOPLE'S REPUBLIC OF CHINA

Z. Li, S.W. Inst Physics, PEOPLE'S REPUBLIC OF CHINA

Prof. J.A.C. Cabral, Instituto Superior Tecnico, PORTUGAL

Prof. M.A. Hellberg, Univ. of Natal, S. AFRICA

Prof. D.E. Kim, Pohang Inst. of Sci. \& Tech., SO. KOREA

Prof. C.I.E.M.A.T. Fusion Division Library, SPAIN

Dr. L. Stenflo, Univ. of UMEA, SWEDEN

Library, Royal Inst. of Technology, SWEDEN

Prof. H. Wilhelmson, Chalmers Univ. of Tech., SWEDEN

Centre Phys. Des Plasmas, Ecole Polytech, SWITZERLAND

Bibliotheek, Inst. Voor Plasma.Fysica, THE NETHERLANDS

Asst. Prof. Dr. S. Cakir, Middle East Tech. Univ., TURKEY

Dr. V.A. Glukhikh,Sci. Res. Inst. Electrophys.I Apparatus, USSR

Dr. D.D. Ryutov, Siberian Branch of Academy of Sci., USSR

Dr. G.A. Eliseev, I.V. Kurchatov Inst., USSR

Librarian, The Ukr.SSR Academy of Sciences, USSR

Dr. L.M. Kovrizhnykh, Inst. of General Physics, USSR

Kerntorschungsanlage $\mathrm{GmbH}$, Zentralbibliothek, W. GERMANY

Bibliothek, Inst. Für Plasmaforschung, W. GERMANY

Prof. K. Schindler, Ruhr-Universitát Bochum, W. GERMANY

Dr. F. Wagner, (ASDEX), Max-Planck-Institut, W. GERMANY

Librarian, Max-Planck-institut, W. GERMANY 

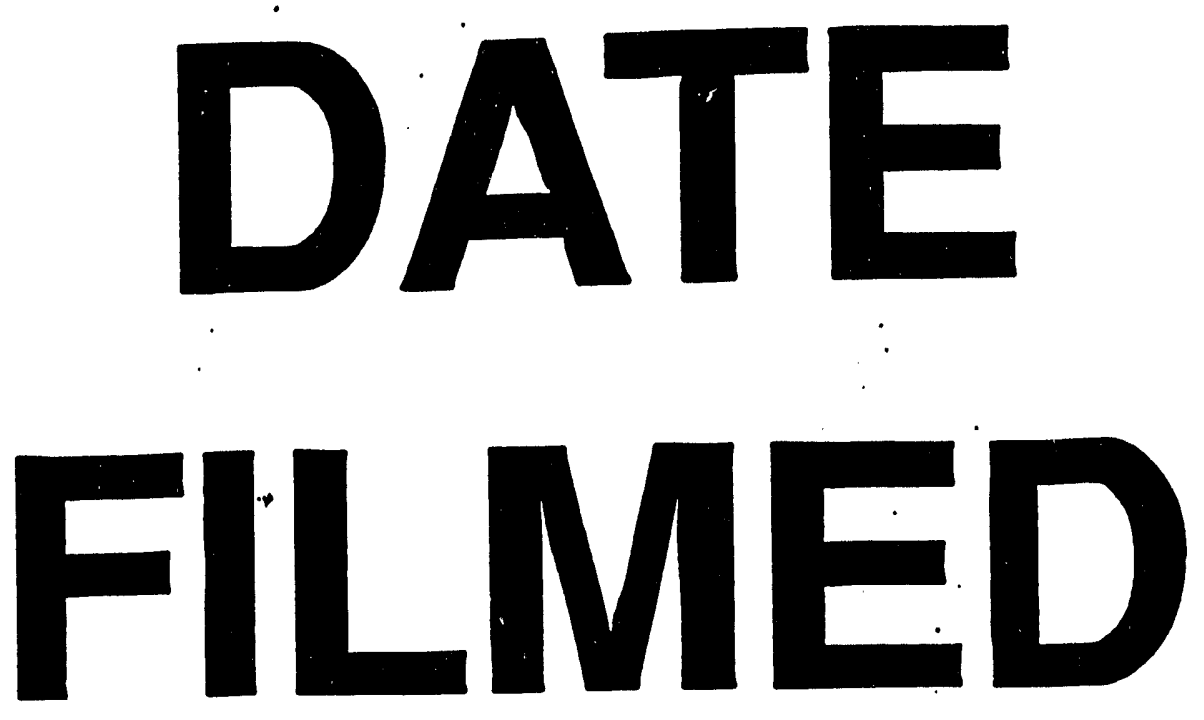

$2 / 8 / 94$
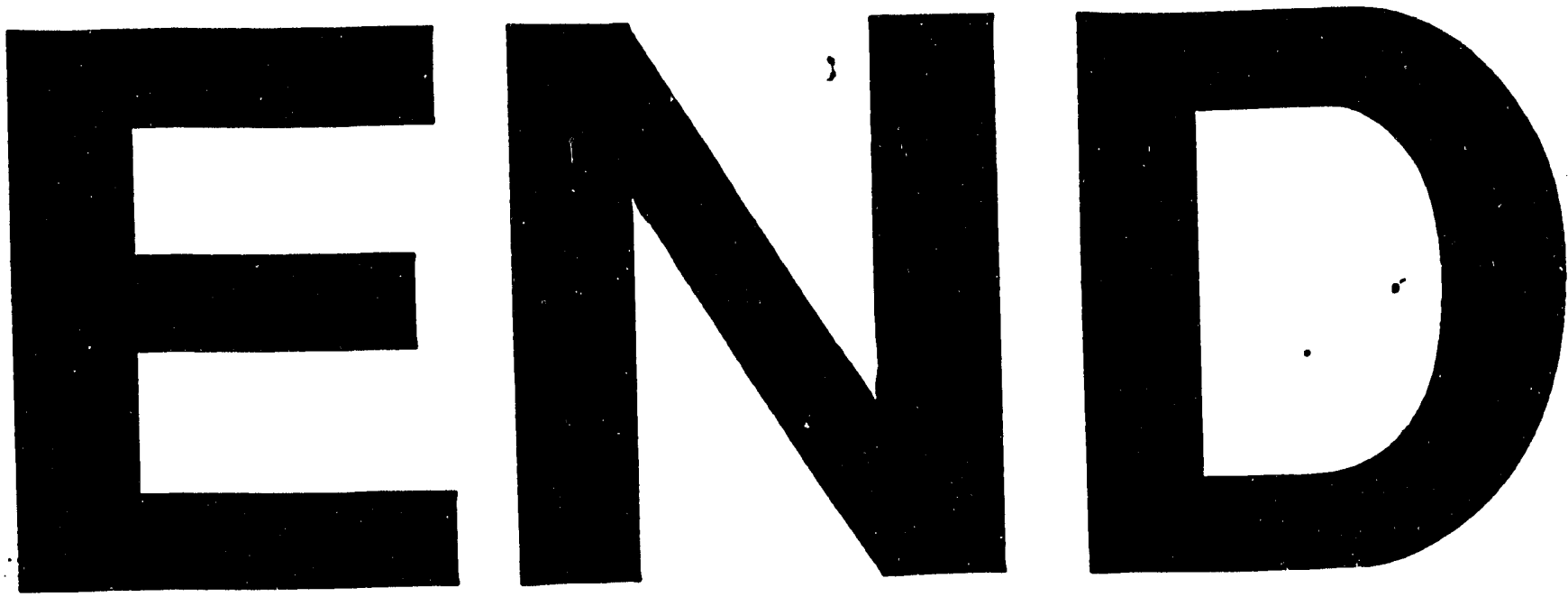
